\title{
Spatial and spatiotemporal dynamics of visceral leishmaniasis in an endemic North-eastern region of Brazil
}

\author{
Ândria Silveira Almeida, ${ }^{1}$ Caíque Jordan Nunes Ribeiro, ${ }^{2}$ Camila Caroline Carlini, ${ }^{1}$ \\ Rogério Silva Santos, ${ }^{3}$ Allan Dantas dos Santos, ${ }^{4}$ Débora Santos Tavares, ${ }^{5}$ Karina Conceição \\ Gomes Machado de Araújo, ${ }^{2}$ Tatiana Rodrigues de Moura, ${ }^{2,3}$ Priscila Lima dos Santos ${ }^{1,2,5}$
}

${ }^{1}$ Postgraduate in Applied Health Sciences, Federal University of Sergipe, Lagarto; ${ }^{2}$ Postgraduate in Health

Sciences, Federal University of Sergipe, São Cristóvão; ${ }^{3}$ Department of Pharmacy, Federal University of

Sergipe, Lagarto; ${ }^{4}$ Postgraduate in Nursing, Federal University of Sergipe, São Cristóvão;

${ }^{5}$ Department of Health Education, Federal University of Sergipe, Lagarto, Sergipe, Brazil

\begin{abstract}
Visceral Leishmaniasis (VL) is a neglected disease with increasing incidence in Brazil, particularly in the North-eastern. The aim of this study was to analyze the spatial and spatiotemporal dynamics of VL in an endemic region of North-eastern Brazil, between 2009 and 2017. Using spatial analysis techniques, an ecological and time series study was made regarding VL cases in Sergipe filed as notifiable disease events. With data from the
\end{abstract}

Correspondence: Karina Conceição Gomes Machado de Araújo, PostGraduate Program in Health Sciences, Federal University of Sergipe, Av. Marechal Rondon, s/n, Jd. Rosa Elze, São Cristóvão, SE, 49100000, Sergipe, Brazil.

Tel: $+55.7998826-7771$.

E-mail: kkkaraujo2006@yahoo.com.br

Key words: Epidemiology; morbidity and mortality indicators; visceral leishmaniasis; spatial analysis; serial temporal studies; Brazil.

Funding: MS/CNPq/FAPITEC/SE/SES No 06/2018 protocol 019.203.00933/2018-0

Ethical considerations: This study used aggregated secondary data in the public domain in line with the recommendation of both the Helsinki Declaration and resolution 466/2012 from Brazil's National Health Council. All data analyzed and included was anonymous, thus negating the need for the Free, Prior and Informed Consent. The research was approved by the Research Ethics Committee of the Federal University of Sergipe (number: 2.537.671).

Conflict of interests: The authors declare no potential conflict of interests.

Received for publication: 5 April 2020.

Accepted for publication: 2 July 2020.

CCopyright: the Author(s), 2020

Licensee PAGEPress, Italy

Geospatial Health 2020; 15:885

doi:10.4081/gh.2020.885

This article is distributed under the terms of the Creative Commons Attribution Noncommercial License (CC BY-NC 4.0) which permits any noncommercial use, distribution, and reproduction in any medium, provided the original author(s) and source are credited.
Brazilian Institute of Geography and Statistics (Instituto Brasileiro de Geografia e Estatística, IBGE), a digital population and cartographic baseline was established. Segmented linear regression was used to examine the temporal trends. The statistical analysis methods of Global and Local Moran' I, local Bayesian empirical methodology and spatial-temporal scanning were used to produce thematic maps. High instances were found among adults, males, urban residents, non-Whites and persons with low levels of education. A decrease in the recovery rate and an increase in the proportion of urban cases and lethality was found. A heterogeneous VL distribution with spatiotemporal agglomeration on the seaside of the state was seen in Sergipe. To better manage the disease, new research is encouraged together with development of public health strategies. Further, improving health care networks, especially primary care, is suggested as this approach has a key role in health promotion, prevention and monitoring of the most prevalent diseases.

\section{Introduction}

Visceral Leishmaniasis (VL) is caused by an intracellular protozoan of the Leishmania genus and transmitted by various species of the sand fly Lutzomya. It is a neglected serious systemic infection which can be fatal if not diagnosed and treated within the appropriate time. Its distribution is broad endemicity in 12 countries in the Americas. Between 2001 and 2017, 59,769 cases were reported, with in an average of 3,516 cases per year. In Brazil, around 96\% $(57,582)$ of the cases are reported $(\mathrm{MoH}, 2017$; WHO, 2015; Hailu et al., 2016; Bezerra et al., 2018).

Brazil had 33,080 confirmed cases of VL between 2009 and 2017 , out of which $54.6 \%(18,060)$ were in the North-eastern. The state of Sergipe had 556 confirmed cases in this period with 254 of those cases in the capital Aracaju, which is considered endemic by the Department of Integrated Health Information (Departamento de Informática do Sistema Único de Saúde, DATASUS) due to a large distribution and high lethality rate in several places of the city (DATASUS, 2019). The urban areas of Sergipe have expanded rapidly and some regions have therefore become essentially urban and peri-urban. This provides opportunities for increased numbers of several infectious Neglected Tropical Diseases (NTDs; Costa de Albuquerque et al., 2017), such as tuberculosis (Lima et al., 2019), schistosomiasis (dos Santos et al., 2019), leprosy (de Souza et al., 2019) and leishmaniasis (Boaz et al., 2019). 
Lethality due to VL is increasing in the state. This trend as well as the increased incidence in immunocompromised populations, such as those infected by the Human Immunodeficiency Virus (HIV) and the elderly have captured the attention of health professionals and the scientific community. Gaining more knowledge regarding transmission dynamics of this parasitic infection is therefore imperative (Santos et al., 2019), while geospatial methods and spatial statistics are useful for defining risk areas, which assists the development of efficient strategies for tracking and prevention (Campos et al., 2017). This study aimed to analyse the spatiotemporal dynamics of VL in the endemic North-eastern Brazil between 2009 and 2017.

\section{Materials and methods}

\section{Design and study area}

This is a time series and ecological study employing spatial analysis techniques and includes cases of VL in Sergipe between 2009 and 2017, which allows assessment in three 3-year periods, as recommended by the Brazilian Ministry of Health (MoH, 2019). The states' 75 cities were used as analysis units. As stated by Brazilian Institute of Geography and Statistics (Instituto Brasileiro de Geografia e Estatística, IBGE), Sergipe is situated in Northeastern Brazil and has an estimated population of 2,298,696 on an area of $21,915 \mathrm{~km}^{2}$ (Figure 1). It is the smallest state in the Brazil and characterized by social disparities with its south-eastern region being the most developed region (Lima et al., 2019).

\section{Data source}

The System for Information on Notifiable Diseases (Sistema de Informação de Agravos de Notificação, SINAN) of DATASUS provided the morbidity data (DATASUS, 2019). The shapefile extension containing the population estimates of Sergipe and its digital cartographic bases using the geographical coordinate system, presented by the Geocentric Reference System for the Americas (Sistema de Referencia Geocéntrico para las Américas, SIRGAS, 2000) were sourced from the IBGE (2019).

\section{Variables and measures}

The main measure of the study was the VL incidence rate, which was tabulated for each city as follows: by year (between 2009 and 2017), by triennium (2009-2011, 2012-2014 and 20152017), by age ( $\leq 4$ years old, 5-19 years old, 20-39 years old, 40-59 years old and $\geq 60$ years old) and by sex. For every period, the crude incidence rate was deduced from dividing the average number of cases by the estimated central population. Dividing the triennial average number of cases by the estimated central population (2010, 2013 and 2016, respectively) gave the triennial rates. The data were smoothed using the local Bayesian empirical method, which improved the stability of the incidence rates, especially in cities with small populations (Assunção et al., 1998).

The risk of transmission in the area analysed was based on data from the Epidemiological Surveillance Guide of Brazil's Health Office $(\mathrm{MoH}, 2019)$ and stratified using the following classification: sporadic transmission $(<2.4$ cases $/ 100,000$ persons $)$, mild transmission ( $\geq 2.4$ to $<4.4$ cases $/ 100,000$ persons) and intense transmission ( $\geq 4.4$ cases $/ 100,000$ persons).

The prevalence of VL was a secondary measure of the study along with lethality (direct or indirect), percentage of VL-HIV co-

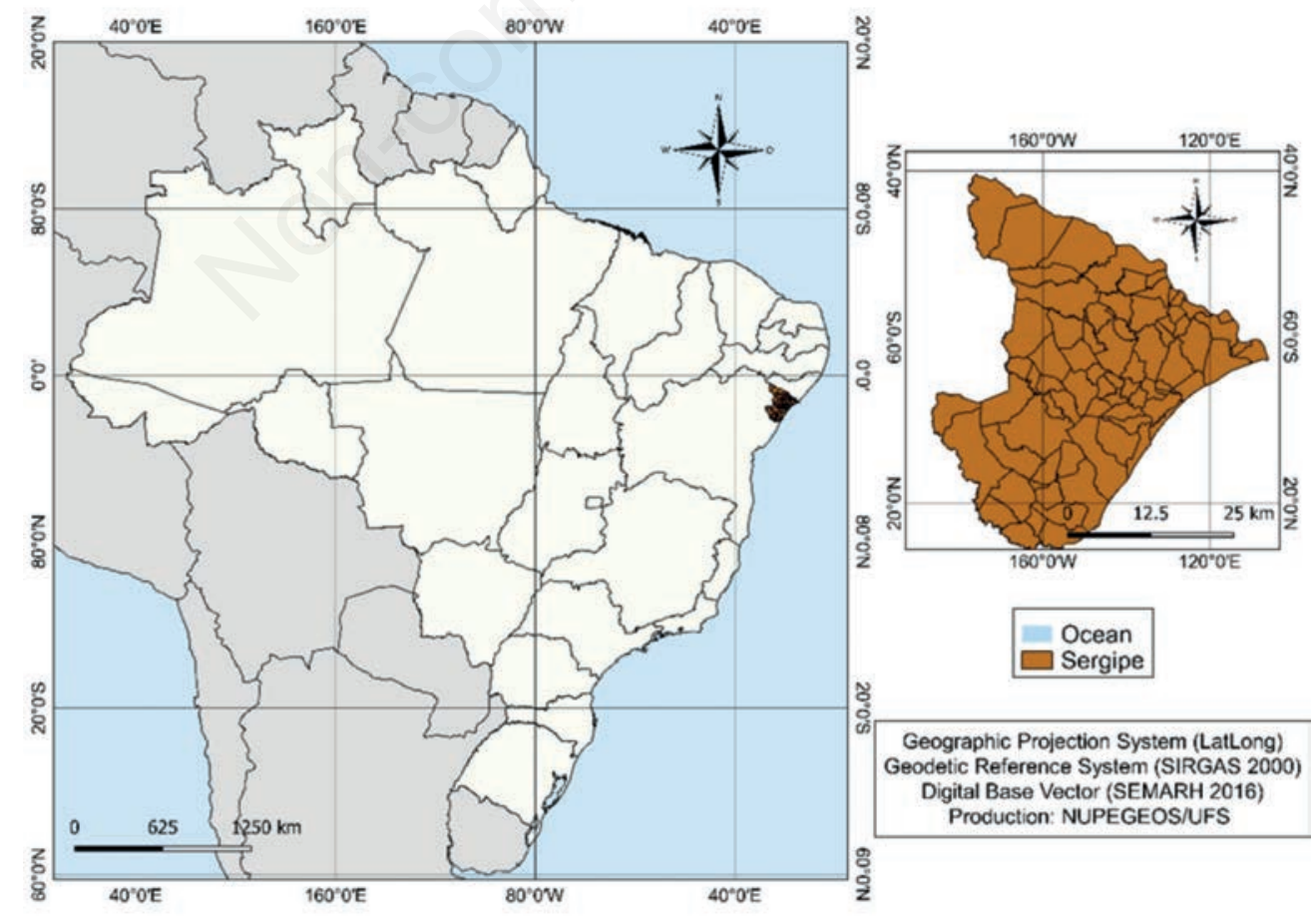

Figure 1. Study area. 
infection and proportion of cities with VL transmission. Epidemiological characteristics, such as skin colour, age group, sex, level of education, residence area, type of case and outcome were provided in simple and relative frequencies.

\section{Analysis of the temporal trends}

Using segmented linear regression (joinpoint), the temporal trends were analysed and classified as increasing, decreasing or stable. Using the Monte Carlo permutation test, the best segment of the model was selected. The year of event occurrence was deemed an independent variable and the crude prevalence rates (in the population), crude incidence rates (with respect to sex, population and age range), percentage of VL-HIV co-infection, crude mortality and lethality (in the population) and proportion of the cities with transmission were deemed as dependent variables. The Annual Percentage Changes (APCs) were tabulated for each segment and deemed significant at a P-value $<0.05$ and their IC95\% did not include zero. The final model chosen was the most adjusted, enabling better representation of the trend and the lowest number of inflexion points (Antunes and Cardoso, 2015).

\section{Spatial analysis}

Choropleth maps were initially established to show the spread of the crude VL incidence rates, then the smoothed rates were also displayed graphically via maps. These two were stratified based on the risk of transmission. Global Moran's I was tabulated in order to analyse the spatial autocorrelation via first-degree proximity matrix as per the contiguity criterion. When autocorrelation was identified, the Local Moran's I (LISA) was applied to show the occurrence of spatial clusters of cities with high VL transmission and also to show a distribution diagram in four quadrants per city: Q1 (high VL incidence rates and the same in neighbouring cities), Q2 (low incidence VL rates and the same in neighbouring cities), Q3 (low VL incidence rates and high rates in neighbouring cities) and Q4 (high VL incidence rates and low rates in neighbouring cities). "Moran Maps" diagrams were applied, only using statistically significant results $(\mathrm{P}<0.05)$.

\section{Spatiotemporal analysis}

Identification of high-risk spatiotemporal clusters for VL transmission and estimation of relative risks (RR) regarding the neighbourhood was done via retrospective spatiotemporal scan statistics. Poisson's probability distribution was used for the following: no geographic overlapping of the clusters, circular clusters, oneyear aggregation time, a 50\% maximum size of the spatial cluster of the risk population and 50\% maximum time of the temporal cluster of the study period. The primary cluster (most likely) was identified using Likelihood Logarithmic Ratio (LLR) and shown in a map. The results were considered significant if the P-value was $<0.05$ via 999 Monte Carlo permutations (Kulldorff, 1997).

\section{Software used}

Microsoft Office Excel 2016 (Microsoft Corporation; Redmond, WA, USA) was used for storage and preparation of the data; and QGis 3.4.11 (QGIS Development Team Open Source Geospatial Foundation Project) for map preparation. TerraView 4.2.2 (www.inpe.br) and GeoDa ${ }^{\mathrm{TM}} 1.14$ (Anselin, 2005) were used for spatial analyses. Joinpoint Regression ${ }^{\mathrm{TM}} 4.6$ (US National Cancer Institute, Bethesda, MD, USA) was used for temporal trend analysis. SaTScan ${ }^{\mathrm{TM}}$ 9.6 (Harvard Medical School, Boston and
Information Management Service Inc., Silver Spring, MD, USA) was used for spatiotemporal analysis.

\section{Results}

In Sergipe, 813 suspected cases of VL were reported between 2009 and 2017, out of which 556 were confirmed, with an average of 62 cases/year. The annual incidence ranged from 2.03 to 4.01 cases per 100,000 persons (Figure 2). The predominant characteristics of the VL cases in the state were: adults (47.7\%), non-White $(83.1 \%)$, limited education $(41.9 \%)$, new cases $(93.5 \%)$, males $(70.9 \%)$, residing in urban area $(70.7 \%)$, and that evolved to recovery $(82.7 \%)$. The overall lethality of VL was $13.0 \%$ (72 deaths) within the period with 35 cases of VL-HIV co-infection $(6.3 \%)$, (Table 1).

Table 1. Epidemiological characteristics of VL cases from 2009 to 2017, Sergipe, Brazil.

\begin{tabular}{|c|c|c|}
\hline Variables & $\begin{array}{c}\text { Frequency } \\
\text { n (556) }\end{array}$ & $\%$ \\
\hline $\begin{array}{l}\text { Diagnosed cases } \\
\text { New } \\
\text { Recurrent } \\
\text { Imported } \\
\text { Ignored }\end{array}$ & $\begin{array}{c}520 \\
23 \\
4 \\
9\end{array}$ & $\begin{array}{l}93.53 \\
4.14 \\
0.72 \\
1.62\end{array}$ \\
\hline $\begin{array}{l}\text { Sex } \\
\quad \text { Male } \\
\text { Female }\end{array}$ & $\begin{array}{l}394 \\
162\end{array}$ & $\begin{array}{l}70.86 \\
29.14\end{array}$ \\
\hline $\begin{array}{l}\text { Age group } \\
\text { 0-4 years } \\
5-19 \text { years } \\
20-39 \text { years } \\
40-59 \text { years } \\
\geq 60 \text { years } \\
\text { Ignored }\end{array}$ & $\begin{array}{c}132 \\
130 \\
144 \\
121 \\
28 \\
1\end{array}$ & $\begin{array}{r}23.74 \\
23.38 \\
25.90 \\
21.76 \\
5.04 \\
0.18\end{array}$ \\
\hline $\begin{array}{l}\text { Race } \\
\text { White } \\
\text { Non-white } \\
\text { Ignored }\end{array}$ & $\begin{array}{c}60 \\
462 \\
34\end{array}$ & $\begin{array}{c}10.79 \\
83.09 \\
6.12\end{array}$ \\
\hline $\begin{array}{l}\text { Residence area } \\
\text { Urban } \\
\text { Rural } \\
\text { Peri-urban } \\
\text { Ignored }\end{array}$ & $\begin{array}{c}393 \\
127 \\
27 \\
9\end{array}$ & $\begin{array}{c}70.68 \\
22.84 \\
4.86 \\
1.62\end{array}$ \\
\hline $\begin{array}{l}\text { Years of schooling } \\
\quad<8 \\
\geq 8 \\
\text { Ignored }\end{array}$ & $\begin{array}{c}233 \\
62 \\
261 \\
\end{array}$ & $\begin{array}{l}41.91 \\
11.15 \\
46.94\end{array}$ \\
\hline $\begin{array}{l}\text { VL-HIV coinfection } \\
\text { Yes } \\
\text { No } \\
\text { Ignored }\end{array}$ & $\begin{array}{c}35 \\
453 \\
68\end{array}$ & $\begin{array}{l}6.29 \\
81.4 \\
12.2\end{array}$ \\
\hline $\begin{array}{l}\text { Clinical outcome } \\
\text { Discharge by cure } \\
\text { Treatment abandonment } \\
\text { Death by VL } \\
\text { Transference to another state } \\
\text { Ignored }\end{array}$ & $\begin{array}{c}460 \\
12 \\
72 \\
5 \\
7\end{array}$ & $\begin{array}{c}82.73 \\
2.16 \\
12.95 \\
0.90 \\
1.26\end{array}$ \\
\hline
\end{tabular}


Table 2 shows the results of segmented linear regression used to analyse the temporal trends of VL epidemiologic indicators. The VL incidence (APC: -0.5; IC95\%: -7.1 to 6.2 ) and prevalence (APC: -0.5 ; IC95\%: -7.1 to 6.5 ) were found to be stable. The portion of the cities where the transmission of VL commonly occurs was stable (APC: 5.0; IC95\%: -1.5 to 12.0), (Figure 3). No significant annual increase of new cases was seen when sex and age ranges were considered. There was, however, an upward trend of cases in the urban area (APC: 3.2 ; IC95\%: 0.2 to 6.3). Although the mortality trend was flat (APC: 10.3 ; IC95\%: -0.1 to 21.9 ), over the years, the recovery percentage had decreased (APC: -1.5 ; IC95\%: -2.9 to -0.1 ) while the lethality had increased (APC: 11.3 ; IC95\%: 0.4 to 23.4 ).

Spatial dynamics of the intensity of the VL transmission is shown in Figure 4 with national stratification using the three-year base. The spatial distribution in Figure 4 shows the crude incidence rates $(\mathrm{A})$ and the smoothed incidence rates $(\mathrm{B})$. In both cases, the persistent concentration of cities with moderate to high VL transmission along the seaside is remarkable, especially in the Northeastern, which corresponds to the middle sertão region, and in the metropolitan area. Maps of spatial distribution of the average incidence rates in the entire period of study (2009-2017) were established. Figure 5 shows the distribution of the crude incidence rates (A), and the smoothed rates (B). Noteworthy is the clustering of cities with high transmission along the seaside, similar to the patterns shown in Figure 4.

Global Moran's $I$ statistics of the average incidence rates of the entire period (2009-2017) were tabulated. Significant spatial autocorrelation was seen when the smoothed rates $(I=0.707 ; \mathrm{P}=$ $0.001)$ and crude rates $(\mathrm{I}=0.25 ; \mathrm{P}=0.003)$ were analyzed, which demonstrates the existence of a spatial dependence in the VL distribution in Sergipe.

Univariate LISA, subsequently performed with statistically significant represented by "Moran Maps" allowed us to identify the cities categorized as per local indicators (Figures 5C and 5D). The high-risk spatial clusters were found to be grouped on the seaside of

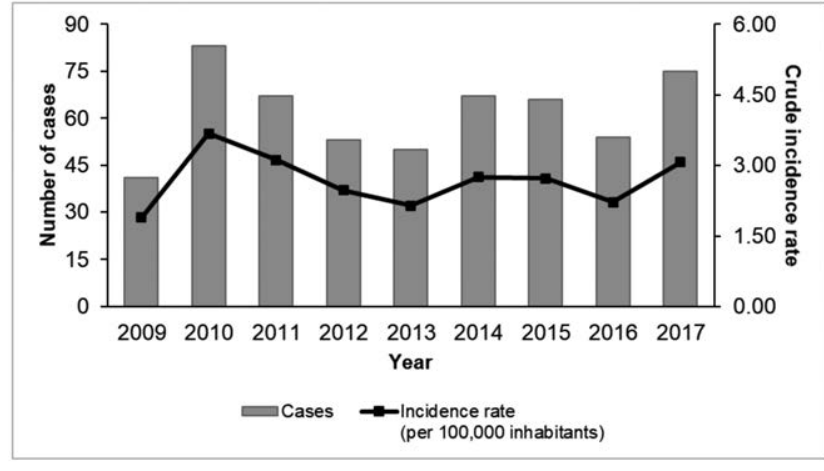

Figure 2. VL reported cases and crude incidence rate in Sergipe, 2009-2017.

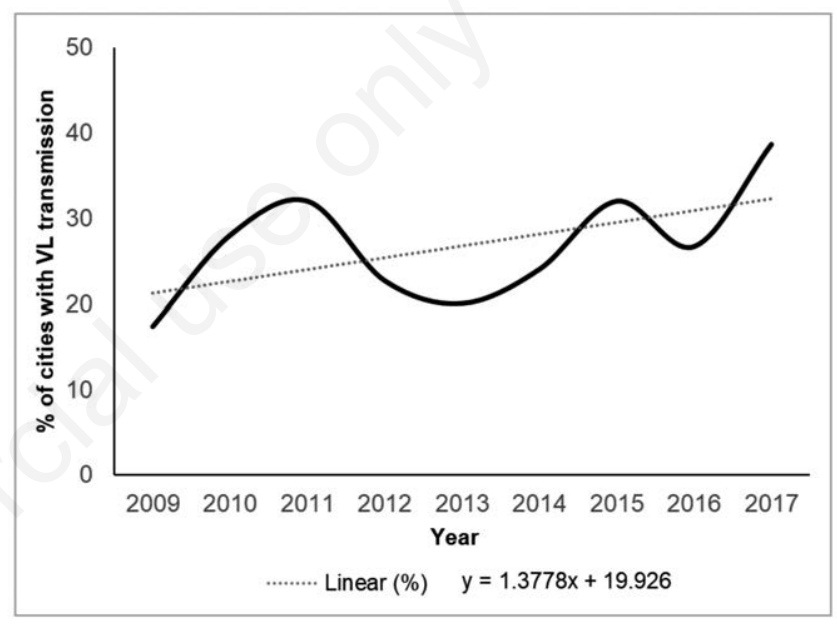

Figure 3. Cities VL transmission trends, from 2009 to 2017, Sergipe, Brazil.

Table 2. Temporal trends of VL epidemiological indicators.

\begin{tabular}{|c|c|c|c|}
\hline Indicator/Variable & Period & APC $(95 \% \mathrm{CI})$ & Trend \\
\hline Crude prevalence rate (per 100,000 hab.) & $2009-2017$ & $-0.5(-7.1$ to 6.5$)$ & Stable \\
\hline $\begin{array}{l}\text { Crude incidence rate (per 100,000 hab.) } \\
\text { General }\end{array}$ & $2009-2017$ & $-0.7(-7.1$ to 6.2$)$ & Stable \\
\hline $\begin{array}{l}\text { Sex } \\
\text { Male } \\
\text { Female }\end{array}$ & $\begin{array}{l}2009-2017 \\
2009-2017\end{array}$ & $\begin{array}{l}0.2(-8.2 \text { to } 9.3) \\
-2.6(-11.7 \text { to } 7.5)\end{array}$ & $\begin{array}{l}\text { Stable } \\
\text { Stable }\end{array}$ \\
\hline $\begin{array}{l}\text { Age group } \\
\quad \leq 4 \text { years } \\
5 \text {-19 years } \\
\text { 20-39 years } \\
\text { 40-59 years } \\
\geq 60 \text { years }\end{array}$ & $\begin{array}{l}2009-2017 \\
2009-2017 \\
2009-2017 \\
2009-2017 \\
2009-2017\end{array}$ & $\begin{array}{l}-5.4(-13.6 \text { to } 3.5) \\
-5.3(-15.5 \text { to } 6.0) \\
1.9(-10.0 \text { to } 15.4) \\
7.7(-3.3 \text { to } 19.9) \\
2.8(-13.3 \text { to } 21.8)\end{array}$ & $\begin{array}{l}\text { Stable } \\
\text { Stable } \\
\text { Stable } \\
\text { Stable } \\
\text { Stable }\end{array}$ \\
\hline $\begin{array}{l}\text { Proportion of cases per residence area } \\
\text { Urban } \\
\text { Rural }\end{array}$ & $\begin{array}{l}2009-2017 \\
2009-2017\end{array}$ & $\begin{array}{l}3.2^{*}(0.2 \text { to } 6.3) \\
-4.2(-10.9 \text { to } 3.0)\end{array}$ & $\begin{array}{l}\text { Upward } \\
\text { Stable }\end{array}$ \\
\hline Cure rate $(\%)$ & $2009-2017$ & $-1.5^{*}(-2.9$ to -0.1$)$ & Downward \\
\hline Crude mortality rate (per 100,000 inhabitants) & $2009-2017$ & $10.3(-0.1$ to 21.9$)$ & Stable \\
\hline Lethality rate (\%) & $2009-2017$ & $11.3^{*}(0.4$ to 23.4$)$ & Upward \\
\hline Proportion of cities with LV transmission & $2009-2017$ & $5.0(-1.5$ to 12.0$)$ & Stable \\
\hline
\end{tabular}


the state and especially in the metropolitan area, which includes the capital Aracaju. The cities classified as Q3 (Low/High) and Q4 (High/Low) also need attention at as they may either be affected or may influence the VL transmission in the neighbouring cities. Finally, space-time scan statistics identified a statistically significant spatiotemporal grouping of VL in the general population (LLR = 31.95; $\mathrm{P}<0.001$ ), which included 157 new VL cases between 2010 and 2013 in the cities Aracaju, Estância, Itaporanga d'Ajuda, Salgado and São Cristóvão, with a crude annual incidence rate of $5 / 100,000$ persons $(\mathrm{RR}=2.25)$, (Figure 5E).

\section{Discussion}

Despite international efforts to control the disease, eventually aiming at eradication, VL remains a serious public health problem in temperate and tropical areas of the world. We analyzed the spatial and spatiotemporal dynamics of VL between 2009 and 2017 in North-eastern Brazil, which is endemic. The results show that there has not been a reduction of disease incidence in Sergipe but rather an increase in disease lethality and a reduced recovery rate. This indicates the control of VL has not been successful.

This study shows a higher VL prevalence in men, as pointed by other epidemiological studies, probably due to genetic factors and a different lifestyle with an increased contact to peri-urban areas and rural settings, either to work or housing (Santos et al., 2018; Góes et al., 2012; da Rocha, 2018). Moreover, recent studies in Sergipe show an upward trend in the age range of VL cases over the years, with adults representing the majority of incident cases (Góes and Jeraldo, 2013; Goes et al., 2014; Santos et al, 2018).

Hence, the data indicate an upward trend of cases in urban areas. This is believed to be due to fast environmental alterations due to anthropic action, with migration to peripheral urban areas leading to increased human interaction with wild animals and dogs in the face of the easy adaptation in residence surroundings by the sand fly vector Lutzomya longipalpis (WHO, 2015; Lane, 2016; Toledo et al., 2017; Góes and Jeraldo, 2013; Barbosa et al., 2014; Campos et al., 2017). The fast-paced urbanization process with a lack of planning may be a factor in the dynamics of several diseases vector-borne diseases such as VL, with the transmission chain becoming more complex than in rural area (Gontijo and Melo, 2004). A higher VL prevalence in a population with limited education was revealed in this research, and this may be related to the higher risk of contracting the disease due to demographic, social and economic aspects. Dos Santos Sousa et al. (2018) have highlighted a correlation between a higher level of education $(>11$ years of study) and a lower VL incidence ( $4.9 \%$ of the total figure), suggesting that the high prevalence of VL among those with limit-

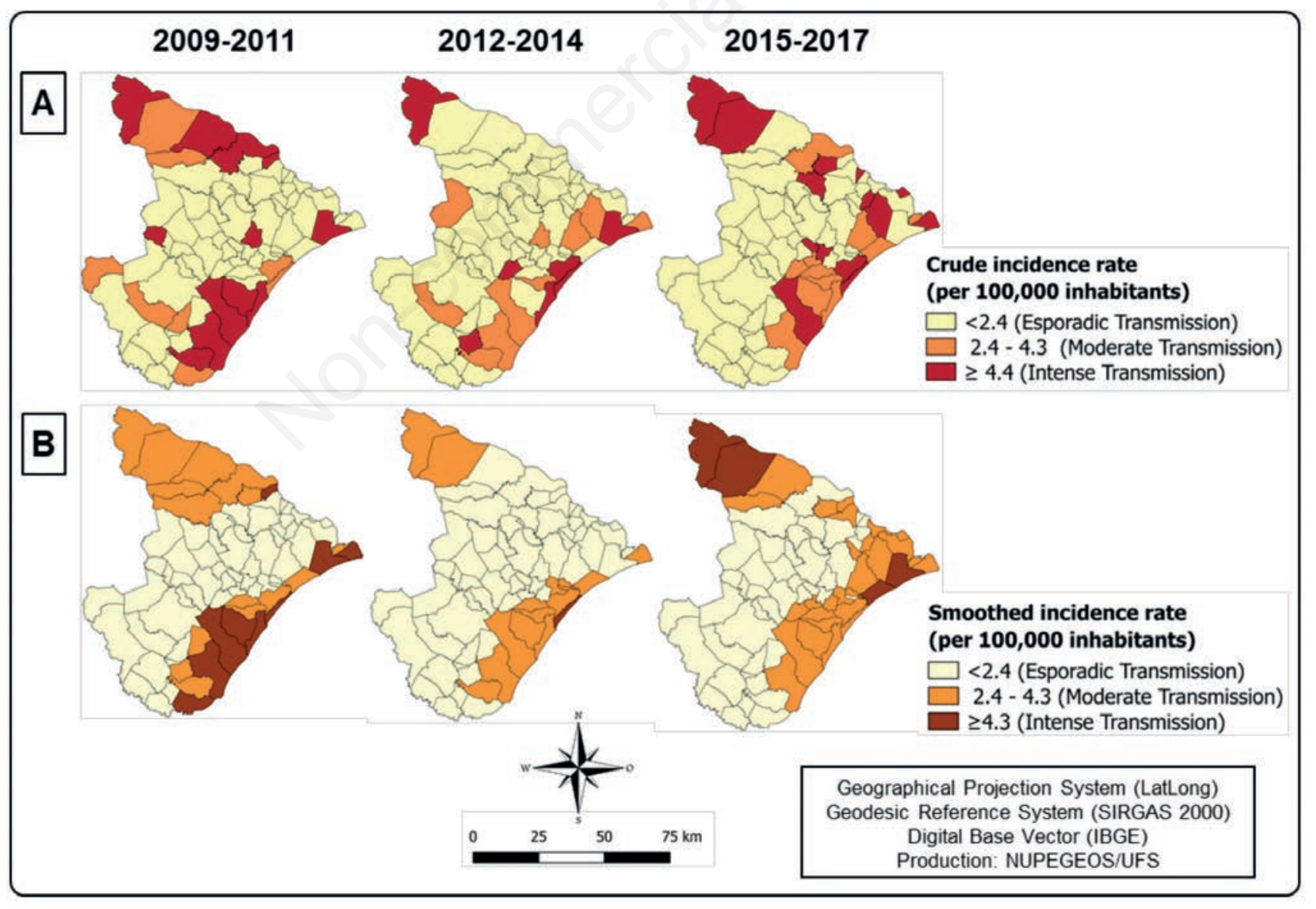

Figure 4. Spatial dynamics, from 2009 to 2017, Sergipe, Brazil. A) Crude incidence rates distribution; B) Smoothed incidence rates distribution (Local Empirical Bayes). 
ed education is due to weaker epidemiological control, a situation likely connected with a broader access to information on preventive measures by those with higher education.

Noteworthy is that VL-HIV co-infections have increased worldwide, e.g., as shown by a study conducted in Sergipe between 1999 to 2015, the authors found an increase in the lethality indicator to $6.3 \%$ from $4.5 \%$ over the study period (Góes and Jeraldo, 2013). The higher VL-HIV co-infection rate can have led to a general increase in disease lethality in the state, since coinfected patients have a more pronounced symptomatology, such as coughing, weight loss and reduced recovery rates (Santos et al., 2018).

The VL lethality rate $(13 \%)$ in Sergipe raises concern, since it is higher than Brazil and North-eastern region mean rate, $7.9 \%$ and $7.8 \%$, respectively (DATASUS, 2019). In different periods, Ceará and Rio Grande do Norte states (Brazil) showed a lethality rate below 7\%, while Pernambuco, geographically closer to Sergipe, presented a $12.3 \%$ rate, from 2006 to 2015 (Cavalcante et al., 2019; Lima et al., 2018; dos Santos Sousa et al., 2018). Moreover, patients older than 60 years of age are 14.2 times more likely than 5-14 years old ones to die from VL, in Piauí, also located in the North-eastern region of Brazil (Sena, 2015) The increase of VL lethality demonstrated herein may be associated to a delay in the diagnosis and disease control/treatment in the primary care, along with difficulties to access the University Hospital, the only one specialized in VL treatment at Sergipe. Mendes et al. (2016) high-

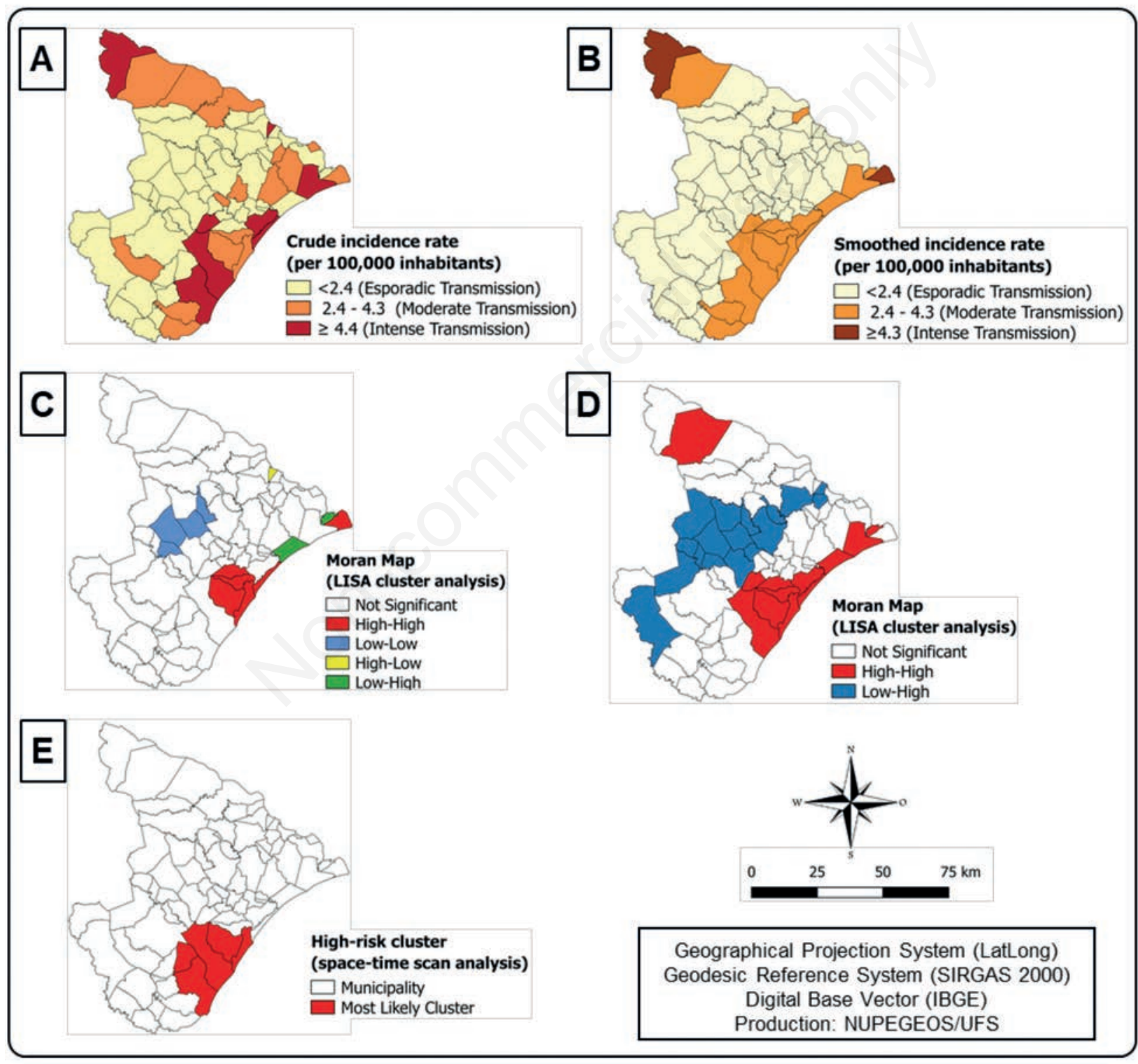

Figure 5. VL spatial, temporal and space-time clustering distribution, from 2009 to 2017, Sergipe, Brazil. A) Spatial distribution of VL crude incidence rates; B) Spatial distribution of VL smoothed incidence rates; C) Moran map showing high-risk clusters related to VL crude incidence rates; D) Moran map showing high-risk spatial clusters related to VL smoothed incidence rates; E) Spatio-Temporal analysis thematic map. 
light evidence of a relationship between climatic variables such as temperature, precipitation, humidity and the transmission of vector diseases such as leishmaniasis in the North-eastern of Brazil. These authors report the highest level of transmission of VL during and right after the rainy season, a time corresponding to the peak of insect density in urban environments and the outskirts of cities. In addition, clustering of cases was observed in the coastal area, mostly in the metropolitan region of Aracaju. Likewise, it was recently observed that this region has environmental peculiarities (high humidity, deforestation and vacant building lots) together with poor living conditions, factors that can favour VL transmission, the dynamics of which are known to be seasonal and dependent on the distribution of sand flies and climatic conditions that influence vector density. The increase in VL cases in the interior of Sergipe may be explained by these characteristics observed near cities with a high density of rivers and canals along with residences with much vegetation and debris (Campos et al., 2017).

While the seaside is the state's most economically developed region, considerable social inequality exists due to the fast-paced urbanization of the region, which promotes the formation of areas of poverty (Lima et al., 2019) where the population is vulnerable and lives in social deprivation. In Bihar, India, VL has been found to impact the poorest of the poor (Boelaert et al., 2009) and recent study results in Brazil demonstrate that disparities in poverty, income distribution, limited education and fragile life conditions all contribute to a high VL mortality (Nunes et al., 2020). Even though the capital Aracaju has the highest number of confirmed cases, statistically significant spatiotemporal clusters were found in other cities such as Estância, Itaporanga d'Ajuda, Salgado and São Cristóvão where expansion of the disease was found throughout the analyzed period. A previous study detected VL in $75 \%$ of Sergipe's cities between 2009 and 2016, with a distribution in all regions of the state from inland areas to the seaside (Santos et al., 2018). It should be noted that VL is a Neglected Tropical Disease (NTD) and while Brazil expands, the North-eastern has the highest number of identified VL cases. There was a space-time agglomeration in the state of Sergipe and the capital Aracaju is considered endemic, with focus on a growing trend of cases in the urban area. This dynamic is due to anthropogenic action, with rapid environmental changes and migration of the population to the peripheral urban areas. In addition, there were higher case rates in workingage males, which has a key impact on the individual and social economy leading to higher government spending. Another concern regards the lethality of the disease, which can be statistically related to the increases in HIV-LV co-infected patients and limited access to the specific treatment needed, given there is only the University Hospital of Aracaju to deal with the situation.

Our conclusions regarding the timing an localization of $\mathrm{VL}$ clusters turned out to be similar with other studies in Sergipe analyzing the spatiotemporal distribution of leprosy (Hansen's disease), (de Souza et al., 2019) and that of tuberculosis (2001-2016), (Lima et al., 2019). This is of concern since overlapping both timewise and geographically is a potential threat of overwhelming the health care system to handle different diseases in the territory.

Reducing social inequalities could be an important pathway to approach leishmaniasis, combined with public policies focused on the local reality, with investment in improved handling of cases and surveillance systems, and whose implementation is supported by a focused research agenda (Romero and Boelaert, 2010; Hailu et al., 2016; Werneck, 2016). The control of VL must additionally be based society actions, such as the health education development initiatives, keeping dogs responsibly and individual control and prevention measures, such as using leashes containing insecticides (Costa et al., 2018).

Given that techniques for spatiotemporal analysis allowing priority area identification of target disease control actions are considered to be incorporated into the surveillance system, synergic efforts should be made for wiping out diseases that specifically affect the vulnerable sectors of the population. To reach this goal, the primary care services must be improved as they represent the preferred entry to the health system and are responsible for longitudinal follow-up activities. It is important to rethink the management of the whole VL programme enabling professionals and providing fast tests for early diagnosis and treatment, as well as facilitating the design and advertising of vector control actions and canine cases not generally accessible to society.

\section{Conclusions}

The present study enabled spatial and spatiotemporal dynamics analysis of VL in the state of Sergipe, Brazil, during the period of 2009 to 2017 . VL clearly stands out as a persistent public health issue in the state, given that there is no reduction of its incidence.

The results indicate a predominance of new cases in specific groups, such as adults, males, those with limited education and urban area residents. A greater number of cases on the seaside of the state were further observed, in particular in the metropolitan area. Worth mention is that despite the use of secondary data, likely due to case under-reporting, the study is relevant for the understanding of VL in the state, useful for the development of new research and the conception of strategies in public health for VL control and surveillance.

\section{References}

Anselin L, 2005. Exploring Spatial Data with GeoDaTM: A Workbook. 1. ed. Urbana: Center for Spatially Integrated Social Science. Available from: https://www.geos.ed. ac.uk/ gisteac/fspat/geodaworkbook.pdf

Antunes JLF, Cardoso MRA, 2015. [Uso da análise de séries temporais em estudos epidemiológicos.] Epidemiologia e Serviços de Saúde 24:565-76. [Article in Portuguese].

Assunção RM, Barreto SM, Guerra HL, Sakurai E, 1998. [Mapas de taxas epidemiológicas: uma abordagem Bayesiana.] Cad Saúde Pública 14:713-23. [Article in Portuguese].

Barbosa DS, Belo VS, Rangel MES, Werneck GL, 2014. Spatial analysis for identification of priority areas for surveillance and control in a visceral leishmaniasis endemic area in Brazil. Acta Trop 131:56-62.

Bezerra JMT, de Araújo VEM, Barbosa DS, Martins-Melo FR, Werneck GL, Carneiro M, 2018. Burden of leishmaniasis in Brazil and federated units, 1990-2016: Findings from Global Burden of Disease Study 2016. PLoS Negl Trop Dis 12:e006697.

Boaz R, Corberán-Vallet A, Lawson A, de Ferreira-Lima FE, Donato LE, et al., 2019. Integration of animal health and public health surveillance sources to exhaustively inform the risk of zoonosis: An application to visceral leishmaniasis data in Brazil. Spat Spatiotemporal Epidemiol 29:177-85. 
Boelaert M, Meheus F, Sanchez A, Singh SP, Vanlerberghe V, et al., 2009. The poorest of the poor: a poverty appraisal of households affected by visceral leishmaniasis in Bihar, India. Trop Med Int Health 14:639-44.

Campos RNS, Tunon GIL, Cunha LCS, Magalhaes LS, Moraes J, et al., 2017. Epidemiological aspects and spatial distribution of human and canine visceral leishmaniasis in an endemic area in northeastern Brazil. Geospat Health 12:503.

Cavalcante FRA, Cavalcante KKS, Florencio CMGD, Moreno JO, Correia FGS, Alencar CH, 2019. Human visceral leishmaniasis: epidemiological, temporal and spacial aspects in Northeast Brazil, 2003-2017. Rev Inst Med Trop S Paulo 62:e12.

Costa de Albuquerque MA, Dias DM, Vieira LT, Lima CA, Silva AM, 2017. Mortality trends for Neglected Tropical Diseases in the State of Sergipe, Brazil, 1980-2013. Infect Dis Poverty 6:20.

Costa DNCC, Bermudi PMM, Rodas LAC, Nunes CM, Hiramoto RM, et al., 2018. Human visceral leishmaniasis and relationship with vector and canine control measures. Rev Saúde Pública 52:92.

da Rocha ICM, dos Santos LHM, Coura-Vital W, da Cunha GMR, Magalhães FC, et al., 2018. Effectiveness of the Brazilian Visceral Leishmaniasis Surveillance and Control Programme in reducing the prevalence and incidence of Leishmania infantum infection. Parasit Vectors 11:586.

DATASUS, 2019. [Department of Informatics of the Unified Health Systems.] Available from: http://datasus.saude.gov.

de Souza CDF, Rocha VS, Santos NF, Leal TC, de Paiva JPS, et al., 2019. Spatial clustering, social vulnerability and risk of leprosy in an endemic area in Northeast Brazil: an ecological study. J Eur Acad Dermatol Venereol 33:1581-90.

dos Santos AD, Lima ACR, Santos MB, Alves JAB, Góes MAO, et al., 2019. Spatial analysis for the identification of risk areas for schistosomiasis mansoni in the State of Sergipe, Brazil, 2005-2014. Rev Soc Bras Med Trop 49:608-15.

dos Santos Sousa JMS, Ramalho WM, Melo MA, 2018. Demographic and clinical characterization of human visceral leishmaniasis in the State of Pernambuco, Brazil between 2006 and 2015.Rev Soc Bras Med Trop 51:622-630.

Góes MAO, Melo CMD, Jeraldo VDLS, 2012. [Série temporal da leishmaniose visceral em Aracaju, estado de Sergipe, Brasil (1999 a 2008): aspectos humanos e caninos.] Rev Bras Epidemiol 15:298-307. [Article in Portuguese].

Góes MAO, Jeraldo VDLS, 2013. [Características clínicas e epidemiológicas dos pacientes internados com leishmaniose visceral em hospital de referência.] Rev Soc Bras Clin Med S Paulo 11:227-31. [Article in Portuguese].

Gontijo CMF, Melo MN, 2004. [Leishmaniose Visceral no Brasil: quadro atual, desafios e perspectivas.] Rev Bras Epidemiol 7:7-12. [Article in Portuguese].

Hailu T, Yimer M, Mulu W, Abera B, 2016. Challenges in visceral leishmaniasis control and elimination in the developing countries: A review. J Vector Borne Dis 53:193-8.

IBGE, 2019. [Instituto Brasileiro de Geografia e Estatística.] Avaliable from: http://www.ibge.gov.br. Accessed: Sep 7, 2019. [Website in Portuguese].

Kulldorff MA, 1997. Spatial scan statistic. Commun Stat Theory Methods 26:1481-96.
Lane VM, 2016. [Análise epidemiológica da Leishmaniose visceral humana no Brasil: contribuição as políticas de controle.] Repositório UNB, Brasília [Article in Portuguese]. Available from: https://repositorio.unb.br/handle/10482/21419

Lima ID, Lima ALM, Mendes-Aguiar CO, Coutinho JFV, Wilson ME, et al., 2018. Changing demographics of visceral leishmaniasis in northeast Brazil: Lessons for the future. PLoS Negl Trop Dis 12:e0006164.

Lima SVMA, dos Santos AD, Duque AM, Góes MAO, Peixoto MVS, et al., 2019. Spatial and temporal analysis of tuberculosis in an area of social inequality in Northeast Brazil. BMC Pub Health 19:873.

Mendes CS, Coelho AB, Féres JG, de Souza EC, da Cunha DA., 2016. The impact of climate change on leishmaniasis in Brazil. Ciên Saúde Col 21:263-272.

Ministry of Health, Brazil (MoH), 2019. [Guide to Health Surveillance. 3. ed. Brasília: Ministério da Saúde.] [Website in Portuguese]. Available from: http://bvsms.saude.gov.br/bvs /publicacoes/guia_vigilancia_saude_3ed.pdf

Ministry of Health, Brazil $(\mathrm{MoH}), 2017$. [Ministério da Saúde. Leishmaniose Visceral. Secretaria de Vigilância em Saúde. Departamento de Vigilância Epidemiológica. Coordenação Geral de Doenças Transmissíveis. Outubro, 2017.] [Website in Portuguese]. Available from: https://portalarquivos2. saude.gov.br/images/pdf/2019/janeiro/28/leishvisceral-17novo-layout.pdf

Nunes BEBR, Leal TC, de Paiva JPS, da Silva LF, do Carmo RF, et al., 2020. Social determinants of mortality due to visceral leishmaniasis in Brazil (2001-2015): an ecological study. Rev Soc Bras Med Trop 53:e20190262.

Romero GAS, Boelaert M, 2010. Control of visceral leishmaniasis in Latin America - A systematic review. PLoS Negl Trop Dis 4:e584.

Santos GO, de Jesus NPS, Cerqueira-Braz JV, Santos VS, de Lemos LMD, de Santos GO, 2019. Prevalence of HIV and associated factors among visceral leishmaniasis cases in an endemic area of Northeast Brazil. Rev Soc Bras Med Trop 52:e20180257.

Santos MA, Rodrigues SLC, Nascimento ALF, Rodrigues JS, Góes MAO, 2018. [Leishmaniose Visceral: Características clínicoepidemiológicas de casos e óbitos no estado de Sergipe.] Rev Epidemiol Controle Infecç 8:428-34. [Article in Portuguese].

Sena IVDO, 2015. [Fatores associados ao óbito por leishmaniose visceral em hospital público de referência no estado do Piauí. Acervo FIOCRUZ 616.9364098122.] [Article in Portuguese].

Toledo CRS, Almeida AS, Chaves SAM, Sabroza P, Toledo LM, Caldas JP, 2017. Vulnerability to the transmission of human visceral leishmaniasis in a Brazilian urban area. Rev Saúde Pública 51:49

Werneck GL, 2016. [Controle da leishmaniose visceral no Brasil: o fim de um ciclo?] Cad Saúde Pública 32:1-2. [Article in Portuguese].

WHO, 2015. Working to overcome the global impact of neglected tropical diseases: first WHO report on neglected tropical diseases. Geneva: World Health Organization. Available from: https://apps.who.int/iris/bitstream/handle/10665/44440/97892 41564090 eng.pdf?sequence $=1$ 